\title{
Paraplegia
}

\section{Continuous Infusion of Intrathecal Baclofen: Long-term Effects on Spasticity in Spinal Cord Injury}

\author{
P. G. Loubser, MB, ChB, R. K. Narayan, MD, K. J. Sandin, MD, \\ W. H. Donovan, MD, K. D. Russell, RN \\ The Institute for Rehabilitation and Research, Baylor College of Medicine, One Baylor \\ Plaza, Houston, Texas, 77030, USA.
}

\section{Summary}

The effects of intrathecal baclofen infusion were studied in 9 spinal cord injury patients whose spasticity had been refractory to oral medications. In a two stage, placebo controlled trial, baclofen was administered into the lumbar intrathecal space and subsequent clinical and neurophysiologic changes were assessed.

In stage 1, 9 patients underwent a 5 day percutaneous infusion of baclofen and placebo via an external pump. Ashworth and reflex scores were assessed at time of enrollment, after infusion of that amount of baclofen which provided optimal spasticity control and after intrathecal infusion of placebo. The mean Ashworth grade decreased from $3.78 \pm 1.34$ to $1 \cdot 16 \pm 0.48(p<0.001)$ while mean reflex score decreased from $3.57 \pm 1.05$ to $0.64 \pm 0.87(p<0.001)$. These values differed significantly from those associated with placebo therapy (Ashworth grade-2.54 $\pm 1.04, p<0.001$; reflex score-2.56 $\pm 1.04, p<0.01)$. Objective improvements in functional abilities and independence were noted in 8 patients, while somatosensory and brainstem auditory evoked potentials were unchanged in all patients. Urodynamic evaluation revealed increased bladder capacity in 3 patients, while in 4 no change was observed.

In Stage 2, permanent programmable infusion pumps were implanted in 7 patients who demonstrated a good response during Stage 1. In this group, mean Ashworth score decreased from $3.79 \pm 0.69$ to $2 \pm 0.96(p<0.001)$ and mean reflex score decreased from $3.85 \pm 0.62$ to $2 \cdot 18 \pm 0.43(p<0.001)$. Baclofen dosage increased from $182 \pm 135$ to $528 \pm 266 \mathrm{mcg} /$ day over the 3-22 month follow-up period. Most of the dosage increase occurred within the initial 12 months following infusion pump implantation and tended to plateau thereafter.

Minor complications such as catheter dislodgement/kinking and nausea occurred infrequently while no device related infections were observed. There was no clinical evidence of any significant baclofen neurotoxicity either in Stage 1 or 2. The only ambulatory patient developed marked lower extremity weakness during Stage 1 intrathecal baclofen infusion and was temporarily unable to walk.

We conclude that continuous administration of intrathecal baclofen is an effective and safe modality for spasticity control in patients who are refractory to oral medications. Key words: Baclofen; Infusion pump; Intrathecal injection; Muscle spasticity; Spinal cord injury.

Correspondence to: P. G. Loubser, MB, ChB, TIRR, 1333 Moursund Avenue, Houston, Texas, 77030, USA. 
In 1979, the first successful use of intrathecal opioids in humans was reported and demonstrated prolonged analgesia following drug administration (Wang et al., 1979). Subsequently, the administration of drugs directly into the intrathecal or subarachnoid space has received much attention. Agents applied intrathecally exert their effects directly at receptor sites on the spinal cord, thus bypassing the bloodbrain barrier. Theoretically, this could result in greater therapeutic efficacy with smaller drug doses and hence less systemic toxicity.

Spasticity has continued to be a perplexing problem for clinicians involved in spinal cord injury medicine (Young, 1989). The mainstays of spasticity control include traditional rehabilitative therapies and oral pharmacologic agents such as baclofen, dantrolene, diazepam and newer agents such as clonidine and tizanidine (Donovan et al., 1988). The use of neurodestructive techniques such as chemical or radiofrequency thermal rhizotomy have limitations particularly in patients with incomplete injuries. Newer modalities such as dorsal column stimulation have had limited effectiveness (Dimitrijevic et al., 1986).

The continuing search for effective treatments for spasticity caused by spinal cord injury underwent an important development when the effects of intrathecal baclofen on spasticity were demonstrated. Penn et al. recently reported an encouraging experience with the use of intrathecal baclofen for the treatment of intractable spasticity (Penn et al., 1987, 1989). These reports described the administration of baclofen solution through a surgically implanted, subcutaneous infusion reservoir or pump connected to a catheter which entered the lumbar subarachnoid space. The results of this and other subsequent investigations (Muller et al., 1989, Lazorthes, 1989, Ochs et al., 1989) indicated that intrathecal baclofen produced titratable and reversible control of spasticity, that was predictable and relatively safe, features that were heretofore unavailable. We initiated independent studies in patients served by our regional spinal cord injury center. This paper describes our experience with this modality with particular emphasis on long term rehabilitative issues and the question of tolerance.

\section{Materials and methods}

\section{Patient selection}

Nine patients with traumatic, non-progressive spinal cord injury were studied. In each patient, spasticity was adjudged refractory to conventional treatment modalities including pharmacologic agents (dantrolene, diazepam, clonidine, baclofen, or combinations thereof), physical and occupational therapy, and in certain cases surgical interventions such as epidural spinal cord stimulation (patients 1 and 4), chemical rhizotomy (patient 5) and anterolateral cordotomy (patient 5). Oral baclofen (up to $120 \mathrm{mg}$ /day) was found to have been ineffective in controlling spasticity adequately. One quadriplegic patient with apnea had bilateral phrenic nerve stimulation in situ.

\section{Protocol review}

The study protocol was reviewed by the Institutional Review Board of Baylor College of Medicine and the Research Committee of The Institute for Rehabilitation 
and Research. It was also approved by the Food and Drug Administration for investigational new drug and device applications.

\section{Patient evaluation}

Prior to commencing baclofen administration, patients were weaned off all spasticity medications. This was accomplished initially on an outpatient basis. As spasticity increased markedly, patients were observed in an inpatient setting because of the increased potential for skin breakdown and withdrawal effects. Radionuclide cisternography was performed to assess spinal canal patency. Indium DPTI radioisotope $(1 \mathrm{ml})$ was injected by lumbar puncture at the L3-4 or L4-5 lumbar vertebral interspace. Cerebrospinal fluid (CSF) pressure was measured and CSF samples analysed for chemistry and cytology. The cephalad migration of Indium was tracked by scanning the area over the spinal cord at regular intervals $(6$ hours, 24 hours, and 48 hours) to determine whether isotope had reached the basal cisterns.

Clinical evaluations included assessment of spasticity using the Ashworth scale (Table I) and neurologic reflex scale (Table II), evaluation by physical therapy using the evaluation of functional abilities (EFA, Table III), by occupational therapy using the evaluation of personal independence (EPI, Table IV) and a global assessment scale (a functional assessment points scale developed by Ciba Geigy Pharmaceuticals and used by Medtronic, Inc.). Laboratory evaluations included somatosensory evoked potentials (lumbosacral, cervical and cortical), brainstem auditory evoked responses, polyelectromyography, isokinetic dynamometry, and cystometrography.

Table I Definition of Ashworth Scale-the total Ashworth grade is calculated by summing grades for hip flexion, hip abduction, knee flexion and ankle dorsiflexion on each side and then dividing by eight

\begin{tabular}{ll}
\hline Grade & Degree of muscle tone \\
\hline 1 & No increase in tone \\
2 & Slight increase in tone, giving a 'catch' when affected part is \\
3 & moved in flexion or extension \\
4 & More marked increase in tone, but affected part easily flexed \\
5 & Considerable increase in tone; passive movement difficult \\
\hline
\end{tabular}

Table II Reflex Scale-the total reflex score is calculated by summing the scores from knee and ankle reflexes on each side and then dividing by four

\begin{tabular}{ll}
\hline Score & Description of reflex response \\
\hline 0 & No response \\
1 & Hyporeflexia \\
2 & Normal response \\
3 & Mild hyperreflexia \\
4 & 4 beats clonus \\
5 & Unsustained clonus, $>4$ beats \\
6 & Sustained clonus \\
\hline
\end{tabular}


Table III Evaluation of functional abilities (EFA) - physical therapy

\begin{tabular}{|c|c|}
\hline Transfers & Bed mobility \\
\hline $\begin{array}{l}\text { Wheelchair to bed } \\
\text { Wheelchair to toilet } \\
\text { Wheelchair to tub } \\
\text { Bed to shower/commode chair } \\
\text { Wheelchair to car } \\
\text { Wheelchair to sofa } \\
\text { Wheelchair to chair } \\
\text { Wheelchair to floor }\end{array}$ & $\begin{array}{l}\text { Rolls supine to sidelying } \\
\text { Rolls supine to prone } \\
\text { Supine to sit } \\
\text { Scoots in long sitting } \\
\text { Scoots in supine } \\
\text { Positions self in bed } \\
\text { Self-ROM of LE's } \\
\text { Coughs effectively }\end{array}$ \\
\hline $\begin{array}{l}\text { Wheelchair function } \\
\text { Relieves pressure } \\
\text { Positions self in wheelchair } \\
\text { Positions cushion } \\
\text { Manages wheelchair parts } \\
\text { Propels even terrain } \\
\text { Propels uneven terrain } \\
\text { Manages curbs } \\
\text { Manages ramps } \\
\text { Manages doors } \\
\text { Manages stairs } \\
\text { Proper falling technique } \\
\text { Picks up object from floor }\end{array}$ & $\begin{array}{l}\text { Ambulation } \\
\text { Dons/doffs orthosis } \\
\text { Sit to stand } \\
\text { Floor to standing } \\
\text { Steps into tub/shower } \\
\text { Level surfaces } \\
\text { Unlevel surfaces } \\
\text { Manages curbs } \\
\text { Manges ramps } \\
\text { Manages doors } \\
\text { Manages stairs } \\
\text { Proper falling technique } \\
\text { Picks up object from floor }\end{array}$ \\
\hline $\begin{array}{l}\text { Gait } \\
\text { Pattern } \\
\text { Maximum distance ambulated } \\
\text { Assistive device }\end{array}$ & $\begin{array}{l}\text { Other } \\
\text { Sitting time } \\
\text { Driving skills }\end{array}$ \\
\hline $\begin{array}{l}\text { Grading key } \\
\text { CI: Complete Independence } \\
\text { MI: Modified Independence } \\
\text { SU: Supervision (safety issues } \\
\text { MN: Minimal Assistance (sub } \\
\text { MD: Moderate Assistance (sul } \\
\text { MX: Maximal Assistance (sub } \\
\text { DE: Dependent (subject does } \\
\text { AI: Able to instruct. } \\
\text { DC: Patient declines. }\end{array}$ & $\begin{array}{l}\text { nsistent, w/endurance). } \\
\text { device). } \\
75 \% \text { of task). } \\
70-74 \% \text { of task). } \\
4-49 \% \text { of task). } \\
\text { task). }\end{array}$ \\
\hline
\end{tabular}

The patients were then studied in two stages. In Stage 1, a temporary infusion of baclofen was performed over a 5-day period. The object of this phase was to find a dosage of baclofen that optimally controlled spasticity without resulting in flaccidity, and which was associated with functional improvements and patient satisfaction. A 23-gauge polyethylene catheter was inserted via the L3-4 or L4-5 interspace using a 20-gauge Tuohy needle, and threaded cephalad for $3-5 \mathrm{cms}$. The catheter was connected to a small portable external pump (Graseby MS26-Syringe Driver) which continuously infused baclofen intrathecally at specific predetermined rates. A 12-hour interval was designated as an infusion period, after which the infusion rate was adjusted to achieve spasticity control. Placebo (preservative-free normal saline) was infused for one of these 12-hour periods, which was randomly selected. In order to reduce judgemental bias, each change in dosage was carried out and known by one unblinded physician while each evaluation of spasticity for each infusion period was performed by another physician who was blinded as to the dosage of baclofen (or placebo) administered. 
Table IV Evaluation of personal independence (EPI) occupational therapy

\begin{tabular}{ll}
\hline Communications & Hygiene \\
Ability to signal & Use handkerchief \\
Speak adequately & Wash hands and face \\
Write signature & Brush teeth \\
Write or type $10 \mathrm{wpm}$ & Groom hair \\
Read and turn pages & Shave or make-up \\
Complete phone call & \\
Eating: & Dressing: \\
Eat with fingers & Shoes and stockings on/off \\
Eat with spoon/fork & Slacks or skirt on/off \\
Butter bread & Jacket on/off \\
Cut meat & Slipover garment on/off \\
Move dishes & Trunk support on/off \\
\hline
\end{tabular}

Grading key:

$\mathrm{N}$ : Normal performance.

G: Independent performance for practical purposes.

F: Performance possible but lacks speed or endurance.

P: Partial performance of activity $(>50 \%)$.

T: Partial performance of activity $(<50 \%)$.

O: Activity impossible.

On completion of each 12-hour infusion period, clinical evaluation of hypertonicity and reflexes was repeated. Simple cognitive tasks such as short-term (3 object) memory and mental arithmetic were tested and signs of neurotoxicity were sought. Patients were also questioned regarding the presence of nausea, vomiting, drowsiness, deterioration in bladder function, and change in appetite or sleep pattern. Once the patient and the physicians had determined the optimal dosage of baclofen, patients were encouraged to transfer out of bed and to move about, in order to evaluate their own spasticity. Evaluations of functional abilities and personal independence and follow-up laboratory studies were repeated at this time. Upon completion of Stage 1, the catheter was removed and the findings discussed with the patient. Patients who achieved an improvement in spasticity control and functional abilities during Stage 1 were offered the opportunity to participate in Stage 2: infusion pump implantation.

In Stage 2, the patients were anaesthetised with general anaesthesia via endotracheal tube with controlled ventilation. Using a 14-gauge Tuohy needle, the subarachnoid space was entered via the L3-4 or L4-5 interspace. A 14-gauge catheter (silicon elastomere) was threaded cephalad to lie at the T12-L1 level. The catheter was secured and then tunnelled into a small subcutaneous pocket in the right lower quadrant. A Medtronic $8611 \mathrm{H}$ (Synchromed) infusion reservoir was implanted in this pocket and connected to the catheter. The dosage of baclofen selected for initial continuous infusion via the implanted reservoir was equal to that as determined in Stage 1. The patients were kept under observation for approximately 5 days, during which time dosage adjustments were made, if needed.

Patients are seen on a monthly basis for infusion pump refills. The flow rate is set at $0.6 \mathrm{ml} /$ day which allows refills to be performed every 28 days, since the 
reservoir holds $18 \mathrm{ml}$. The concentration of baclofen placed in the infusion reservoir is varied in order to provide the required daily dosage. Patients return at monthly intervals at which time clinical evaluation of spasticity, reflexes and additional symptoms is performed. Any change in functional activities, independence, or bladder function is noted. Intercurrent rehabilitation and medical problems such as infections are also addressed. The dosage of baclofen is monitored carefully over this period. At these re-evaluations, patients are assessed for the possible development of tolerance to the drug as well as for the presence of urinary tract infection, paronychia, and other factors known to aggravate spasticity. In addition, psychosocial aspects such as work issues, school activities, overall well-being and affect were assessed.

\section{Results}

Ten patients were referred for the study. One patient was withdrawn before enrollment because myelography demonstrated complete obstruction to dye flow at T4 and L4 secondary to severe scarring of the intrathecal space, which would have made catheter placement extremely difficult:

\section{Stage 1: Trial of percutaneous drug infusion}

Nine patients, all male, comprised the cohort for Stage 1 . The mean age was $45 \cdot 6$ $+/-12 \cdot 35$ (range 22-63). Radionuclide cisternography was within normal limits for 8 of 9 patients in this group; one patient demonstrated partial obstruction in the upper thoracic region with elevated cerebrospinal fluid protein levels which was not felt to be a contraindication to further study. Though the patients' spasticity increased with tapering of their oral medications, there were no untoward effects. Vital signs and laboratory values were within normal limits.

Table $\mathrm{V}$ gives the results for each patient before infusion (control), after infusion of placebo and at optimal baclofen dosage. Using the paired student's t-test,

Table V Ashworth grade and reflex score—control (cont), during placebo (plac) and at optimal (opt) baclofen dosage (mcg/day) during Stage 1 (patient numbers correlate in Tables V, VI and VIII)

\begin{tabular}{|c|c|c|c|c|c|c|c|c|c|c|}
\hline \multirow[b]{2}{*}{$\mathrm{Pt}$} & \multirow[b]{2}{*}{ Age } & \multirow{2}{*}{\multicolumn{2}{|c|}{ Injury +}} & \multicolumn{3}{|c|}{ Ashworth } & \multicolumn{3}{|c|}{ Reflex } & \multirow[b]{2}{*}{ Dose } \\
\hline & & & & Cont & Plac & Opt & Cont & Plac & Opt & \\
\hline 1 & 33 & $\mathrm{~T} 8$ & B & 5 & $2 \cdot 75$ & $1 \cdot 25$ & 4 & $4 \cdot 5$ & 0 & 150 \\
\hline 2 & 46 & $\mathrm{C} 4$ & A & $3 \cdot 5$ & $3 \cdot 5$ & 1.5 & 5 & $2 \cdot 75$ & $2 \cdot 5$ & 150 \\
\hline 3 & 61 & $\mathrm{C7}$ & C & 5 & 1.5 & 1 & 4 & 1 & 1 & 375 \\
\hline 4 & 40 & T8 & A & 5 & 3 & 1 & 3 & $3 \cdot 5$ & 1 & 50 \\
\hline 5 & 22 & $\mathrm{C} 2$ & A & $3 \cdot 75$ & $2 \cdot 63$ & 1 & $4 \cdot 5$ & $1 \cdot 75$ & 0 & 150 \\
\hline 6 & 42 & T7 & B & 4 & $4 \cdot 13$ & $2 \cdot 25$ & $4 \cdot 5$ & 3.5 & 0 & 50 \\
\hline 7 & 53 & T12 & $\mathrm{C}$ & $1 \cdot 75$ & 0.75 & 0.5 & $2 \cdot 63$ & $1 \cdot 5$ & $1 \cdot 25$ & 400 \\
\hline $8^{*}$ & 63 & $\mathrm{C} 4 \mathrm{I}$ & D & 1.5 & $1 \cdot 75$ & 1 & $2 \cdot 25$ & $2 \cdot 75$ & 0 & 100 \\
\hline $9^{*}$ & 50 & $\mathrm{C} 8$ & B & $4 \cdot 5$ & $2 \cdot 87$ & 1 & $2 \cdot 25$ & $1 \cdot 75$ & 0 & 50 \\
\hline $\mathbf{x}$ & & & & $3 \cdot 78$ & $2 \cdot 54$ & $1 \cdot 16$ & 3.57 & $2 \cdot 56$ & 0.64 & 163.9 \\
\hline SD & & & & $1 \cdot 34$ & 1.04 & 0.48 & 1.05 & $1 \cdot 14$ & 0.87 & $134 \cdot 1$ \\
\hline
\end{tabular}

+-Level of spinal cord injury and Frankel classification.

*-Did not undergo permanent pump implantation (Stage 2). 
statistically significant differences were found between control and optimal reflex score $(t=7.69, p<0.001)$ and Ashworth grade $(t=6.05, p<0.001)$, between placebo and optimal reflex score $(t=3.68, p<0.01)$ and Ashworth grade $(t=6.0, p<0.001)$ and between placebo and control Ashworth grade $(t=2.95$, $\mathrm{p}<0.02)$. In contrast, no difference was found between control and placebo reflex scores.

Table VI shows the results of the functional evaluations before and at optimal intrathecal baclofen dosage for each patient. With one exception, all patients benefitted markedly in terms of gaining increased independence, of decreasing the time and effort for self-care required of caregivers, or both. The low quadriplegic and paraplegic patients gained increased independence in mobility and self-care. Those patients who were independent in activities of daily living prior to entrance into this study maintained this status while on intrathecal baclofen. The mid- to low-paraplegic patients, whose lower extremity spasticity had been so severe as to

Table VI Assessments of function (grading keys (Tables III and IV)) during Stage 1-before baclofen (Pre) and at optimal (Opt) baclofen dosage

\begin{tabular}{|c|c|c|c|}
\hline $\mathbf{P t}$ & Activity & Pre & Opt \\
\hline \multirow[t]{3}{*}{1} & Transfers & MD & $\mathrm{CI}$ \\
\hline & Self-ROM of LE's & $\mathrm{DE}$ & $\mathrm{CI}$ \\
\hline & Dressing (shoes, slacks) & $P$ & G \\
\hline \multirow[t]{6}{*}{2} & Transfers & $\mathrm{MX}$ & MD \\
\hline & Positions self in bed & $\mathrm{MX}$ & MD \\
\hline & Time needed to range LE's & 60 mins & 20 mins \\
\hline & Sitting Time & 0 mins & 180 mins \\
\hline & Writing & $\mathrm{O}$ & $\mathbf{P}$ \\
\hline & Power-WC use & $\mathrm{DE}$ & MI \\
\hline \multirow[t]{4}{*}{3} & Transfers & MD & SU \\
\hline & Sit to stand & MD & MN \\
\hline & Self-ROM of LE's & $\mathrm{DE}$ & $\mathrm{CI}$ \\
\hline & Dressing (shoes, slacks) & $\mathrm{T}$ & $P$ \\
\hline \multirow[t]{5}{*}{4} & Transfers & MX & $\mathrm{CI}$ \\
\hline & Supine to sit & MD & $\mathrm{CI}$ \\
\hline & Sit to stand & MX & $\mathrm{CI}$ \\
\hline & Dressing & $\mathrm{T}$ & $P$ \\
\hline & Driving & SU & $\mathrm{CI}$ \\
\hline \multirow[t]{5}{*}{5} & Transfers & MX & MD \\
\hline & Time needed to range LE's & 60 mins & 20 mins \\
\hline & Sitting time & 120 mins & $8 \mathrm{hrs}$ \\
\hline & Writing (mouthstick) & $\mathrm{O}$ & G \\
\hline & Diaphragm pacing duration & $6 \mathrm{hrs}$ & $14 \mathrm{hrs}$ \\
\hline \multirow[t]{3}{*}{6} & Transfers & MN & CI \\
\hline & Prone position duration & 0 mins & 20 mins \\
\hline & Standing bars & MN & $\mathrm{CI}$ \\
\hline \multirow[t]{6}{*}{7} & Transfers & MD & CI \\
\hline & Self-ROM of LE's & $\mathrm{DE}$ & CI \\
\hline & Supine to WC (duration) & 5 mins & $1 \mathrm{~min}$ \\
\hline & Sitting time & $2 \mathrm{hrs}$ & $3 \mathrm{hrs}$ \\
\hline & Dressing time & 20 mins & 10 mins \\
\hline & Driving & SU & $\mathrm{CI}$ \\
\hline \multirow[t]{3}{*}{8} & Self-ROM of LE's & $\mathrm{DE}$ & CI \\
\hline & Sit to stand & $\mathrm{MN}$ & MD \\
\hline & Walking distance & 100 feet & 3 feet \\
\hline \multirow[t]{2}{*}{9} & Self-ROM of LE's & MD & CI \\
\hline & Sit to stand & MD & CI \\
\hline
\end{tabular}


interfere with the ability to drive were able to achieve independence in driving with intrathecal baclofen. Although high quadriplegic patients remained dependent in activities of daily living, caregiver time and effort for daily care such as range of motion, positioning, and transfers decreased markedly.

In one ambulatory motor incomplete patient (Frankel D), reduction of spasticity in the lower extremities was associated with muscle weakness, despite careful titration of intrathecal baclofen, so that ability to ambulate decreased significantly.

Two patients elected not to proceed with follow-up laboratory testing during Stage 1 (see complications below). Seven patients underwent urodynamic assessment before and while on optimal baclofen dosage. Four patients demonstrated no change pre- and post-baclofen: 2 of these continued to have detrussor areflexia, 1 continued to have autonomic dysreflexia at low volumes and 1 continued to have detrussor hyperreflexia with detrussor sphincter dyssynergia. A decrease in the intravesicular pressure after intrathecal baclofen was observed in 3 patients: 1 demonstrated a decrease in maximum pressure from $140 \mathrm{~cm} \mathrm{H}_{2} \mathrm{O}$ to 60 $\mathrm{cm} \mathrm{H}_{2} \mathrm{O}$ while in another a similar drop in pressure from $120 \mathrm{~cm} \mathrm{H}_{2} \mathrm{O}$ at $320 \mathrm{ml}$ to $90 \mathrm{~cm} \mathrm{H}_{2} \mathrm{O}$ at $540 \mathrm{ml}$ was observed, though the post-void residual volume increased from 40 to $310 \mathrm{ml}$ (Fig. 1). The third patient demonstrated a minor decrease in maximal intravescicular pressure from 140 to $130 \mathrm{~cm} \mathrm{H}_{2} \mathrm{O}$.

Seven patients who underwent neurophysiologic testing before and after intrathecal baclofen demonstrated multiple changes including decreased or absent withdrawal from plantar stimulation $(n=4)$, higher thresholds for triggering spasms (cutaneous stimulation, passive movement, volitional manoeuvres) $(\mathbf{n}=2)$ and decrease of minimal voluntary motor control $(n=2)$. One patient had no change in any of the parameters tested. Electromyography of lower extremity musculature confirmed diminished reflex motor activity in 5 patients (Fig. 2). Isokinetic dynamometry revealed a narrowing of the hysteresis loop after baclofen
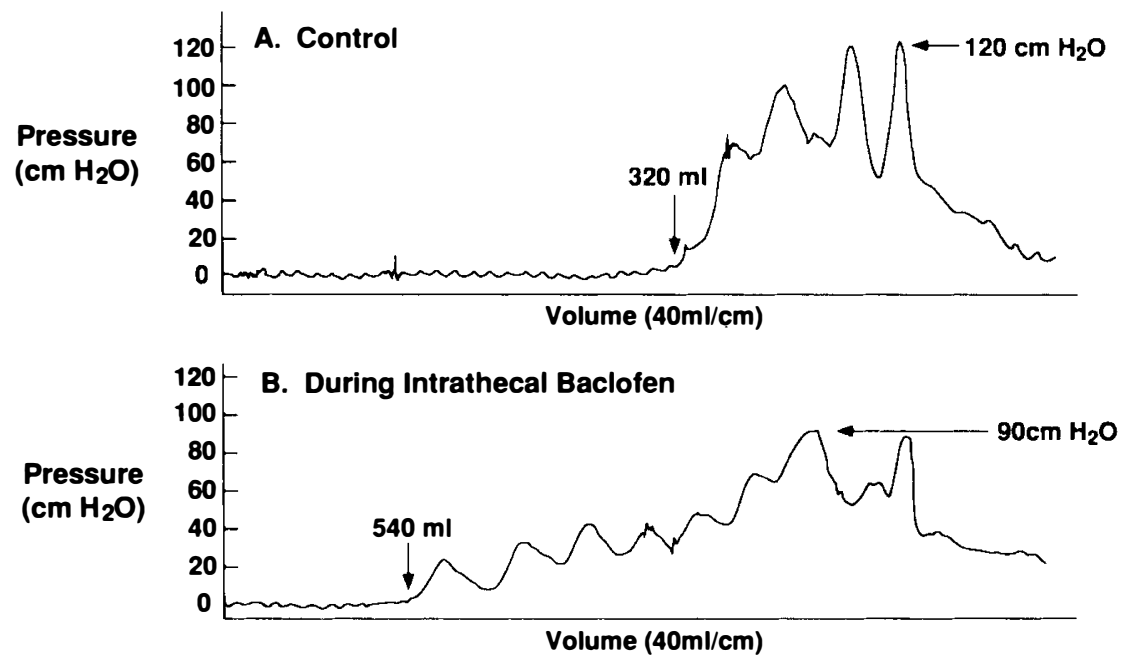

Figure 1 Representative change in cystometrography for patient no. 4. A-Control: bladder contraction to maximum of $120 \mathrm{~cm} \mathrm{H} \mathrm{H}_{2} \mathrm{O}$ after infusion of $320 \mathrm{ml}$. B-During intrathecal baclofen: maximal contraction of $90 \mathrm{~cm} \mathrm{H} \mathrm{H}_{2} \mathrm{O}$ after infusion of $540 \mathrm{ml}$. The time from initial contraction to reach peak pressure is doubled in $\mathbf{B}$. 
A. Control

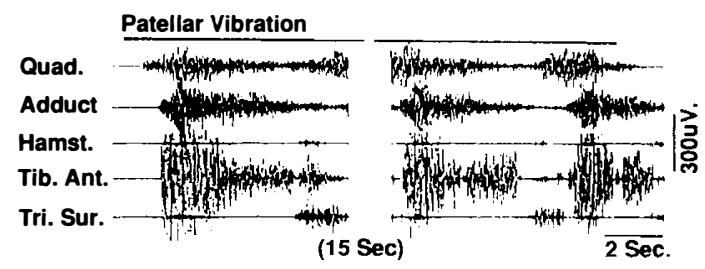

B. During Intrathecal Baclofen

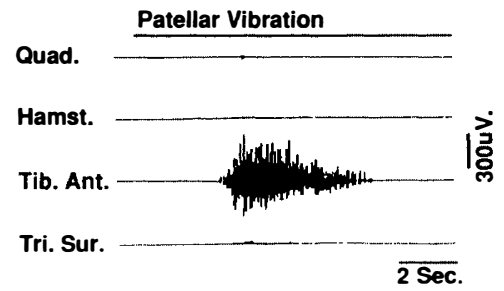

Figure 2 Representative change in polyelectromyography for patient no. 1. A-Control. B-During intrathecal baclofen.
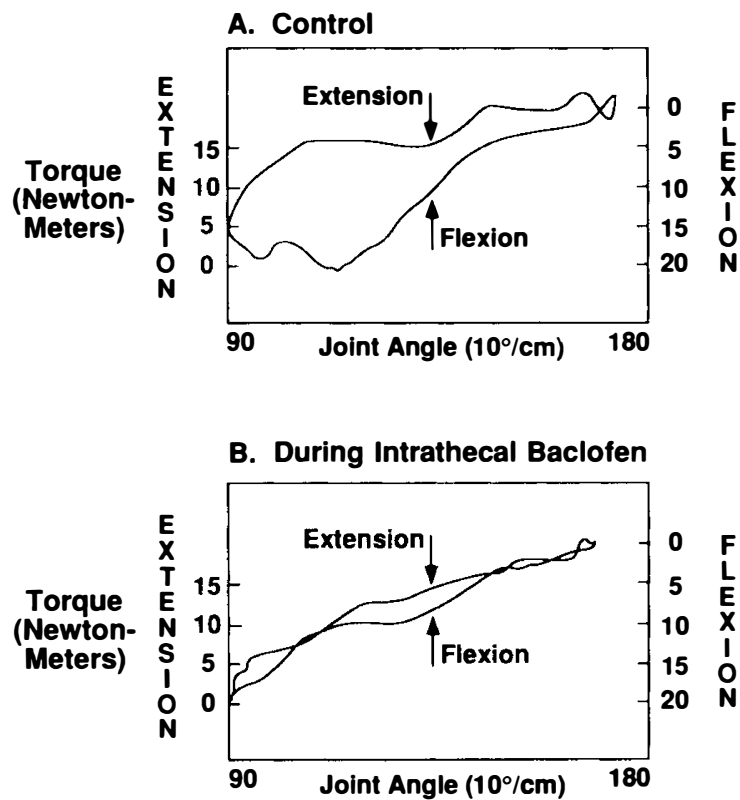

Figure 3 Representative change in isokinetic dynamometry for patient no. 6, obtained by moving the right knee (angular velocity $-120^{\circ}$ per second) through $90-180^{\circ}$ passively. The force produced in hamstrings (extension) and quadriceps (flexion), before $(\mathbf{A})$ and during intrathecal baclofen $(\mathbf{B})$ is demonstrated. 
infusion, indicative of decreased tone in response to stretch in 4 patients (Fig. 3). There was no significant change in somatosensory evoked responses or brainstem auditory responses after infusion of intrathecal baclofen in any of these patients.

Complications during Stage 1 included catheter dislodgement in 2 patients requiring percutaneous replacement. As described above, the only ambulatory patient in this study became weaker in muscles below the spinal cord lesion as a result of intrathecal baclofen, such that he was unable to stand or ambulate even with support. One patient developed mild hypertension (diastolic blood pressure averaging $95 \mathrm{mmHg}$ ) which resolved when intrathecal baclofen was discontinued. Another patient developed rare, asymptomatic, unifocal premature ventricular contractions (PVCs). No patient noted untoward effects of baclofen such as nausea, vomiting, or change in cognitive status during this stage. There were no instances of catheter-related infection or meningitis.

In one patient with severe asthma, pulmonary function tests were performed before and after baclofen infusion. There was significant improvement in the vital capacity, peak flow rate and maximum voluntary ventilation, indicative of considerable improvement in pulmonary function secondary to decreased bronchospasm (Table VII).

Of the 9 patients undergoing Stage 1 evaluations, 2 elected not to undergo follow-up laboratory testing or permanent infusion pump implantation. This included 1 patient who developed muscle weakness, described above, and another patient who despite a good response decided that he had better truncal balance with spasticity than without.

\section{Stage 2: Implantation of permanent infusion pump}

Seven patients underwent infusion pump implantation. These 7 males had an average age of $42 \cdot 4$ years $+/-12 \cdot 8$ (range, 22-61) and mean time interval since spinal injury of $40+/-31$ months (range 6-96). Table VIII reports the date of infusion pump implantation, initial and final Ashworth and reflex scores and the daily dose of intrathecal baclofen at the final assessment. Figure 4 graphically depicts the decrease in mean spasticity ratings for all 7 patients over time of treatment with intrathecal baclofen. In this group, the mean Ashworth score decreased from $3.79+/-0.69$ to $2.00+/-0.96(\mathrm{t}=12.9, \mathrm{p}<0.001)$ and the

Table VII Pulmonary function tests for patient Number 3

\begin{tabular}{lccc}
\hline & Pre-baclofen & During baclofen & Predicted \\
\hline FVC (1) & 2.4 & 3.0 & 3.99 \\
FEV $_{1}(1)$ & 1.3 & 1.95 & 3.02 \\
FEV $_{1} /$ FVC & 0.54 & 0.65 & 0.76 \\
MMEFR (1/sec) $_{\text {PFR }(1 / \mathrm{sec})}$ & 0.7 & 1.3 & 3.6 \\
MVV (1/min) & 372 & 576 & 542 \\
& 66 & 84 & 134 \\
\hline
\end{tabular}

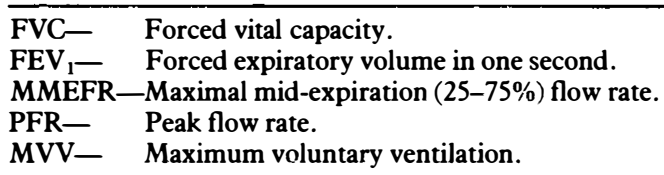


Table VIII Date of infusion pump implantation, Ashworth grade and reflex score-pre (cont) and post (final) pump implantation with final baclofen (bac) dosage (mcg/day) and duration of follow-up (months) during Stage 2

\begin{tabular}{|c|c|c|c|c|c|c|c|}
\hline \multirow[b]{2}{*}{$\mathrm{Pt}$} & \multirow[b]{2}{*}{ Date } & \multicolumn{2}{|c|}{ Ashworth } & \multicolumn{2}{|c|}{ Reflex } & \multirow[b]{2}{*}{ Bac } & \multirow[b]{2}{*}{ Follow-up } \\
\hline & & Pre & Final & Pre & Final & & \\
\hline 1 & $2 / 4 / 88$ & 4 & 2 & 5 & 2 & 350 & 24 \\
\hline 2 & $2 / 25 / 88$ & 3 & $1 \cdot 25$ & 3 & $1 \cdot 75$ & 900 & 24 \\
\hline 3 & $3 / 30 / 88$ & 4 & 2 & 4 & 3 & 876 & 23 \\
\hline 4 & $10 / 11 / 88$ & $3 \cdot 5$ & $1 \cdot 75$ & $3 \cdot 5$ & 2 & 425 & 16 \\
\hline 5 & $3 / 9 / 89$ & 3 & 1 & 3.5 & 2 & 225 & 11 \\
\hline 6 & 3/9/89 & 5 & 4 & 4 & $2 \cdot 5$ & 350 & 11 \\
\hline 7 & $9 / 23 / 89$ & 4 & 2 & 4 & $2 \cdot 5$ & 625 & 5 \\
\hline$x$ & & 3.79 & $\frac{2}{2} \cdots$ & 3.85 & $2 \cdot 18$ & $535 \cdot 8$ & \\
\hline SD & & 0.69 & 0.96 & 0.62 & 0.43 & 269 & \\
\hline
\end{tabular}

\section{Mean Spasticity Ratings Over Treatment}

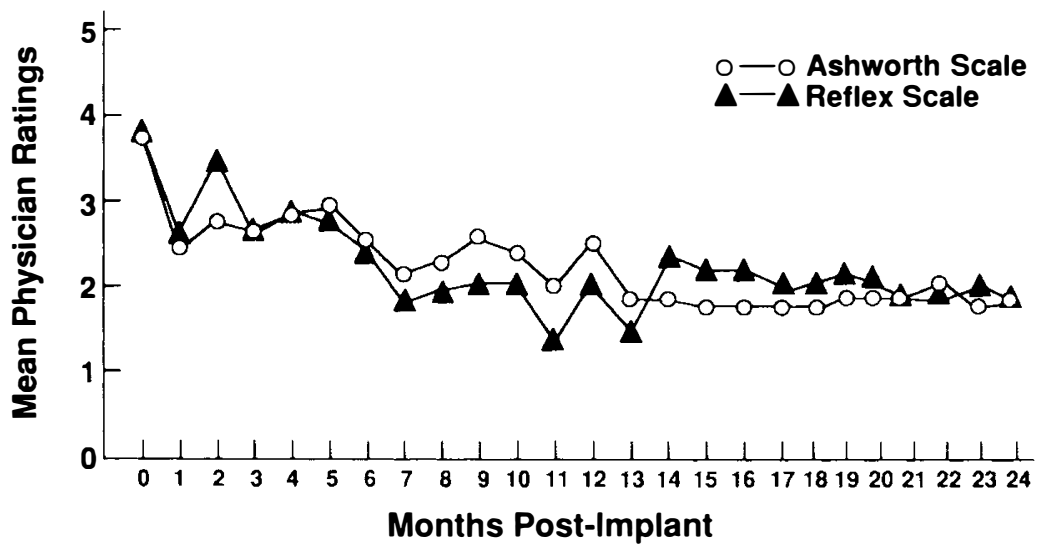

Figure 4 The mean Ashworth grade and reflex scores for all patients at each month post-infusion pump implantation is represented. The sample size decreases over time due to differences among patients in time of enrollment. The goal during follow-up was to maintain patients with some tone rather than flaccidity.

mean reflex score decreased from $3 \cdot 85+/-0.62$ to $2 \cdot 18+/-0.43(t=6 \cdot 76$, $\mathrm{p}<0.001$ ). The mean baclofen dose increased from $163.9 \mathrm{mcg} / \mathrm{day}+/-134.1$ to $535.8 \mathrm{mcg} /$ day $+/-269$. The increase in baclofen dosage required to maintain adequate spasticity control occurred over the initial 12 months following infusion reservoir implantation, reaching a plateau or requiring smaller dosage adjustments thereafter (Fig. 5).

Complications during Stage 2 included catheter dislodgement $(n=1)$ and catheter kinking $(n=1)$ requiring surgical correction without sequelae. One patient whose residual bladder volumes increased with intrathecal baclofen developed recurrent urinary tract infections requiring treatment with antibiotics. One patient reported nausea and vomiting at his highest dose of intrathecal baclofen; when the dose was decreased slightly, his complaints disappeared. One 


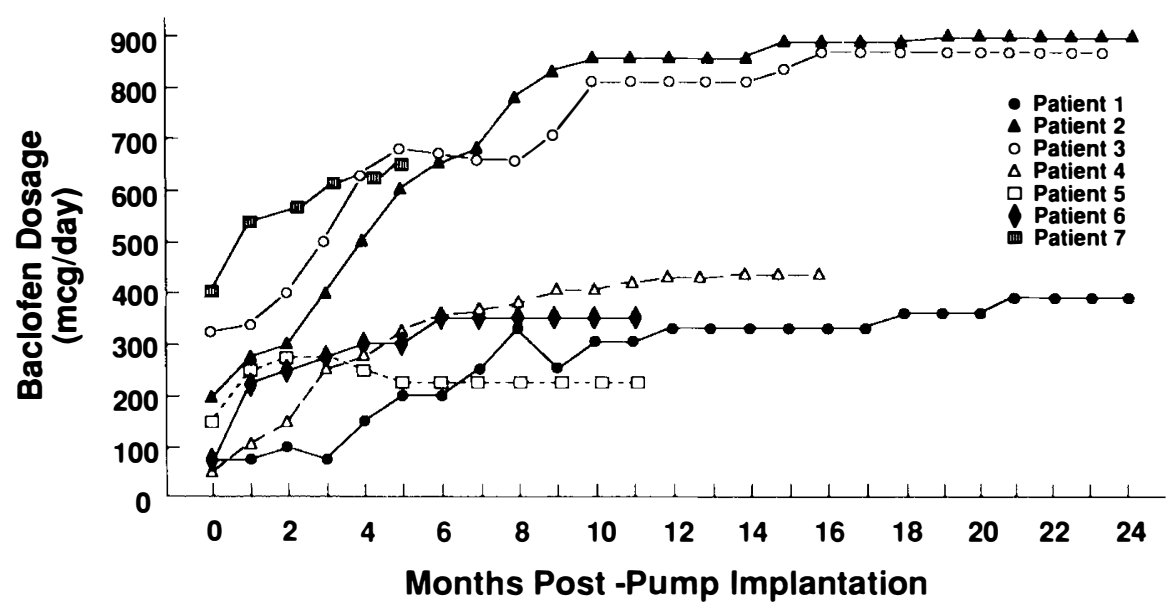

Figure 5 Change in daily baclofen dose over time for each patient in Stage 2.

patient who demonstrated mild blood pressure elevations during Stage 1, developed similar hypertension again during Stage 2 . This has been managed with oral clonidine which has not produced any additive or synergistic effects on spasticity reduction.

There have been no device related infections or baclofen overdoses, and no patient died during either stage. No patient reported neurologic or functional loss while on Stage 2 intrathecal baclofen. Specifically, no patients noted any loss of strength in muscles innervated by segments above their neurologic level. One patient discovered motor control in his legs which had been masked by spasticity; after intrathecal baclofen infusion his Frankel classification changed from B to C. No problems were experienced with infusion pump accuracy or computer hardware. In one patient with bilateral phrenic nerve stimulators in situ, no interference was detected between the infusion pump computerised telemetry and the transmitter-antenna ensemble of the phrenic nerve stimulator. Several patients chose to have the amount of baclofen varied throughout the day, as permitted by the circuitry of the infusion pump which details programming of medication delivery so that more baclofen can be given at night in order to suppress spasms that interfere with sleep. All patients felt subjectively that their spasticity control was improved on intrathecal baclofen as compared to oral medication. No patient required supplementary oral medications to control spasticity after infusion pump implantation. Patients who achieved independence in driving were able to function at a higher level in the community and pursue vocational training aimed at economic self-sufficiency. Three patients previously unable to travel because of spasticity have participated in periods of extended vacation travel. Additionally, one patient reported increased sexual function and gratification.

\section{Discussion}

Gamma-aminobutyric acid (GABA) is a major neurotransmitter mediating presynaptic inhibition in the mammalian central nervous system. The chemical 
<smiles>NCC(CO)c1ccc(Cl)cc1</smiles>

BACLOFEN

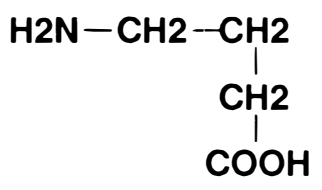

\section{GABA}

Figure 6 Chemical structure of Gamma-aminobutyric acid (GABA) and baclofen (B-4-chlorophenyl GABA).

structure of baclofen (B-4-chlorophenyl GABA, Fig. 6) closely resembles GABA and it is widely held that baclofen is GABA-mimetic producing reduction of spasticity by activation of spinal GABA receptors (Davidoff et al., 1983). GABA (A) receptors located in the ventral horn are bicuccilline sensitive and do not ligand with baclofen; GABA (B) receptors are bicuccilline insensitive and bind baclofen (Bowery et al., 1984). However, experimental studies in animals also suggest that baclofen produces inhibition of S-glutamate, an excitatory neurotransmitter released by primary afferent fibers (Puil, 1983). Furthermore, baclofen is a racemic mixture and studies of its two isomers $(+$ and -$)$ reveal different activities. The $(-)$ baclofen isomer is responsible for most of its reflex-depressant properties (Potashner et al., 1979).

Baclofen administered orally has poor permeability across the blood-brain barrier and the intrathecal route of administration is associated with significantly greater clinical efficacy. In the present study, the required intrathecal dosage was found to be 100 to 250 -fold less than the standard oral dosage. However, if excessive amounts of baclofen are administered intrathecally, central nervous system depression may occur (Penn et al., 1988). Physostygmine has been reported to be an effective antagonist and may be used in a clinical setting to reverse respiratory depression (Muller-Schwefe et al., 1989). The action and distribution of baclofen within the spinal subarachnoid space is governed by CSF pharmacokinetics. During continuous administration of 50 to $1200 \mathrm{mcg} / \mathrm{day}$, lumbar CSF concentration ranges from 130 to $950 \mathrm{ng} / \mathrm{ml}$ while plasma levels are $0-5 \mathrm{ng} / \mathrm{ml}$ (Muller et al., 1989). These findings indicate that systemic absorption of baclofen from the CSF is limited and that the spinal subarachnoid space behaves like a depot. Once delivered intrathecally, baclofen spreads in a cephalad direction affecting initially the lower extremities and then the abdominal muscles and upper extremities. Dilution within CSF occurs as baclofen spreads rostrally. Therefore, increasing the rate of drug delivery is necessary in order to achieve higher CSF baclofen levels in progressively cephalad regions of the subarachnoid space. The present study confirms this, since quadriplegic patients with spasticity of abdominal muscles and upper extremities required higher daily doses than paraplegics. Toxicity occurs when significant amounts of intrathecal baclofen 
reach the midbrain or medulla. Indium cisternography is routinely performed to assess spinal canal patency since this may influence CSF pharmacokinetics. An obstruction in the spinal canal may protect higher central nervous system structures against exposure to baclofen. However, the dilutional effect of cephalad CSF flow is impeded and more baclofen may accumulate proximal to the spinal canal obstruction creating a large intrathecal depot. Potential then exists for systemic absorption and development of plasma baclofen levels that may produce side-effects or toxicity. Experience in one patient with spinal canal obstruction did not reveal any clinical evidence of toxicity, although clearly caution must be exercised in the presence of any anatomic obstruction to CSF flow. In animal studies, brainstem auditory evoked potentials are suppressed by systemically administered baclofen (Martin, 1982) suggesting that auditory evoked potentials may serve as a monitor of any central side-effects following intrathecal application. However, no changes in brainstem auditory evoked potentials were observed in this series.

A trial of continuous percutaneous infusion was used in this study so that a comprehensive evaluation could be performed at a constant baclofen dosage that was judged to be clinically otpimal. Techniques using bolus injections either by percutaneous lumbar puncture or via an implanted subcutaneous port do not provide steady-state pharmacokinetics and are associated with side-effects such as nausea, drowsiness and vertigo.

The demonstration of improved pulmonary function following reduction of spasticity in one patient during Stage 1 suggests that spasticity acted like exercise to induce or provoke bronchospasm. Furthermore, restriction of inspiration secondary to phasic hypertonicity of abdominal muscles was also reduced.

Loss of ability to ambulate in one patient during Stage 1 indicates that intrathecal baclofen may be relatively contraindicated in patients who inherently use stiffness or hypertonicity of the lower extremities for strength and support during ambulation. The findings of Ochs (Ochs et al., 1989), which included muscle weakness and difficulty with titration of intrathecal baclofen in ambulatory patients, confirm our observations.

This study also revealed a significant difference in reflex scores between control and placebo, when theoretically no difference should exist, as demonstrated for the Ashworth Grades. Intrathecal baclofen has a half-life of 8 hours (Muller $e t$ al., 1989). Therefore, it is probable that residual pharmacologic or 'carry-over' effects of intrathecal baclofen are still present after twelve hours of placebo infusion.

Penn at Rush-Presbyterian-St Luke's Medical Center evaluated the effect of intrathecal baclofen on 20 patients with spinal cord injury and multiple sclerosis (Penn et al., 1989). In a radomised double-blind crossover study using baclofen or saline placebo, these patients had a decrease in mean Ashworth score from $4 \cdot 0+/-1 \cdot 0$ to $1 \cdot 2+/-0.4(\mathrm{p}<0.0001)$ and decrease in mean spasm frequency from $3 \cdot 3+/-1 \cdot 2$ to $0 \cdot 4+/-0.8(\mathrm{p}<0.0005)$. The 20 patients then participated in an open long-term trial of continuous infusion of intrathecal baclofen. The patients maintained the response seen initially with mean Ashworth score of $1.0+/-0.1$ and mean spasm score of $0.3+/-0.6$ at follow-up ranging from 10-33 months. Using Penn's data for the 10 patients with spinal cord injury (description of completeness of the lesion is not provided), independent analysis revealed a decrease in mean Ashworth score from 3.74 +/- 1.24 to 1.03 +/- 0.08 
$(\mathrm{t}=6.71, \mathrm{p}<0.001)$, a decrease in mean spasm frequency from $3.15+/-0.75$ to $0.30+/-0.68(\mathrm{t}=8.54, \mathrm{p}<0.001)$, and a mean baclofen dosage of $456.9+/-$ $197 \cdot 7 \mathrm{mcg} /$ day on conclusion of the study.

Using the unpaired Student's t-test and one way ANOVA, comparison of the present study results with Penn's reveals that the initial Ashworth scores are almost identical $(3.79$ to $3 \cdot 74, p=N S)$. The reflex score is a different measure than Penn's spasm frequency score, making comparison impossible. The final baclofen doses do not differ $(535.8$ compared to $456.9 \mathrm{mcg} /$ day; $\mathrm{F}=0.41, \mathrm{p}=\mathrm{NS})$ while the final Ashworth scores are statistically different (2.00 compared to 1.03; $F=10.3, p<0.05)$. This latter finding may be related to length of enrollment in the open phase of the study (5-24 months versus 10-33 months), differences between observers when estimating Ashworth grades, actual timing of spasticity evaluations and degree of hypertonicity deemed optimal by patients and physicians alike. In the present study, assessments of spasticity were recorded at each monthly refill. During the last few days of the monthly refill cycle, a slight increase in spasticity is experienced by most patients as the infusion reservoir empties and this may also have contributed to the observed differences. As noted, baclofen dosage in this study is adjusted for optimal spasticity control which usually approximates Ashworth grade 2. Table IX shows mean data for the two cohorts. In essence, both Penn's and the present study demonstrate the efficacy of intrathecal baclofen in the reduction of spasticity due to SCI.

Functional outcome was evaluated in 8 of Penn's patients (Parke et al., 1989), using Harvey's Patient Evaluation Conference System (Harvey et al., 1981), demonstrating improved performance of bowel and bladder programs in 7 patients. Another study on the effects of intrathecal baclofen on bladder management in 3 Frankel A paraplegic patients demonstrated damping of bladder threshold reflex activity, diminished abnormal sphincter activity and increased bladder storage capacity, in turn producing simplification or functional improvements in bladder management programs (Frost et al., 1989).

In general, the present study supports the above observations for 3 patients. Bladder capacity increased, contractility decreased (lower $P_{\text {iso }}$ and longer rise time to $P_{\text {iso }}$ ) and hypertonicity decreased (longer threshold before initiation of detrusor contraction). In contrast, no change occurred in 4 patients with hypocontractile bladders ab initio.

Drugs that exert their pharmacologic effects by interaction with receptors, i.e. 'receptor-specific ligands,' characteristically show loss of clinical effect during chronic exposure termed 'tolerance.' A fundamental theory of tolerance is that

Table IX Comparison of present study (TIRR cohort; $\mathbf{n}=7$ ) with Rush cohort ( $=10)$; initial (i) and final (f) Ashworth grade (Ash) and final baclofen dosage (bac)

\begin{tabular}{lccc}
\hline TIRR & Ash $(\mathrm{i})$ & Ash $(\mathrm{f})$ & Bac \\
$\mathrm{x}$ & 3.79 & $-\ldots .0$ & 535.8 \\
SD & 0.69 & 0.96 & 269 \\
Rush & & & \\
$\mathrm{x}$ & 3.74 & 1.03 & 456.9 \\
SD & 1.24 & 0.08 & 197.7 \\
\hline
\end{tabular}


receptors 'down regulate' in number or uncouple from their second messenger (e.g. cyclic-AMP) during continued occupancy by the agonist. Furthermore, the agonist may occupy only a fraction of the available receptors leaving a certain reserve of unoccupied receptors. The present study indicates that tolerance to intrathecal baclofen does develop during the initial 12 months following infusion pump implantation. However, the degree of tolerance development appears selflimiting with time and less than that associated with intrathecal opioids. These findings suggest that tolerance to baclofen may be associated with mechanisms other than receptor reserve and down regulation. Further studies are needed in a large cohort over a 3 to 5 year period to determine whether tolerance to baclofen may detract from its long-term clinical efficacy.

In summary, this study has demonstrated using both clinical and laboratory measures of hypertonicity that baclofen infused intrathecally can effectively and safely control spasticity in spinal cord injured patients who have been refractory to all oral anti-spasticity agents. Using an implantable, programmable infusion pump, this study revealed significant decreases in Ashworth and reflex scores, an increase in function and independence without the development of major tolerance or unmanageable side-effects. These findings impact not only the disability produced by spinal cord injury but also the impairment produced by spasticity. Furthermore, titratable reduction of spasticity is clinically useful since flaccidity may be avoided thereby preserving muscle bulk and bone strength.

At present, several studies on intrathecal baclofen are in progress in the United States, while in Europe the use of intrathecal baclofen for spasticity secondary to other neurologic conditions is being investigated (Muller et al., 1989). It is not known whether intrathecal baclofen may also be analgesic although the present study is being expanded to examine its efficacy in chronic spinal cord injury pain. Other intrathecal pharmacologic agents such as morphine, midazolam and tizanidine used for reduction of spasticity are also being evaluated elsewhere. Patients treated with intrathecal baclofen will need further follow-up in order to completely answer questions regarding long term efficacy, safety, functional outcome, and risks of treatment, and to determine whether this therapy might be more beneficial than oral anti-spasticity agents in treating the patient with mild to moderate spasticity.

\section{Acknowledgements}

The authors gratefully acknowledge the assistance of Edward Carter, MD, Milan Dimitrijevic, MD, Keith Light, MD, Lourdes Cuellar, RPh, Das Gupta, PhD, Francis Smith, RN, Carnel Roco, RN, Mandy Smith, LPT, Nancy Pumphrey, OTR and Theresa Gregorio, OTR.

This work was supported in part by the Department of Education; National Institute on Disability and Rehabilitation Research, Grant No. G00853511.

\section{References}

Bowery NG, PrICE GW, Hudson AL et al. 1984 GABA receptor multuplicity. Visualization of different receptor types in the mammalian CNS. Neuropharmacology 23:219-31.

Davidoff RA, HACKMAN JC 1983 Drugs, chemicals, and toxins: their effects on the spinal cord. In: Davidoff RA (ed). Handbook of the Spinal Cord, Volume 1. Marcel Dekker, New York.

DimitrIJEVIC MM et al. 1986 Spinal cord stimulation for control of spasticity in patients with chronic spinal cord injury 1. Clinical observations. Central Nervous System Trauma 3:129-44. 
Donovan WH, CARTER ER, Rossi D et al. 1988 Effect of clonidine on spasticity: a clinical trial. Archives of Physical Medicine and Rehabilitation 69:188-92.

Frost F, NANNINGA J, PENN RD et al. 1989 Intrathecal baclofen infusion: effect on bladder management programs in patients with myelopathy. American fournal of Physical Medicine and Rehabilitation 68:112-5.

HARVEY RF, Jellinek HM. Functional performance assessment: program approach. Archives of Physical Medicine and Rehabilitation 62:456-61.

LAZORTHES Y 1989 Chronic intrathecal administration of baclofen in the treatment of severe spasticity. In: Muller H, Zierski J, Penn RD (eds). Local-spinal Therapy of Spasticity. Springer-Verlag, New York.

MARTIN MR 1982 Baclofen and the brainstem auditory evoked potential. Fournal of Experimental Neurology 76:675-80.

Muller H, Zierski J, Dralle D et al. 1989 Intrathecal baclofen in spasticity. In: Muller H, Zierski J, Penn RD (eds). Local-spinal Therapy of Spasticity. Springer-Verlag, New York.

Muller H, ZiersKi J, Dralle D et al. 1989 Pharmacokinetics of intrathecal baclofen. In: Muller H, Zierski J, Penn RD (eds). Local-spinal Therapy of Spasticity. Springer-Verlag, New York.

OCHS G, STRUPPLER A, MEYERSON BA et al. 1989 Intrathecal baclofen for long-term treatment of spasticity: a multi-centre study. Fournal of Neurology, Neurosurgery and Psychiatry 52:933-39.

MUlleR-SCWEFE G, PENN RD 1989 Physostigmine in the treatment of intrathecal baclofen overdose. Fournal of Neurosurgery 71:273-5.

PARKe B, PENn RD, SAvoy SM et al. 1989 Functional outcome after delivery of intrathecal baclofen. Archives of Physical Medicine and Rehabilitation 70:30-2.

PENN RD, KROIN JS 1987 Long-term intrathecal baclofen infusion for treatment of spasticity. Fournal of Neurosurgery 66:181-5.

PENN RD, SAvoY SM, CoRCos D et al. 1989 Intrathecal baclofen for severe spinal spasticity. New England Fournal of Medicine 320:1517-21.

PotASHNER SH, YASHPAL K, BACKMAN SB et al. 1979 d- and l-baclofen: Differential effects on spinal reflexes. Federation Proceedings 38:900-7.

PuIL E 1983 Actions and interactions of S-glutamate in the spinal cord. In: Davidoff RA (ed). Handbook of the Spinal Cord, Volume 1. Marcel Dekker, New York.

WANG JK, NAUSS LA, ThOMAS JE 1979 Pain relief by intrathecally applied morphine in man. Anesthesiology 50:149-51.

YouNG RR 1989 Treatment of spastic paresis (editorial). New England fournal of Medicine 320:1553-5. 